\title{
O Trabalho em Equipe por meio de Editor de Texto Coletivo ${ }^{1}$
}

\author{
Annie Lilian K. Riccardi - PPGEDU/UFRGS - anniericcardi@hotmail.com \\ Susana Ester López - PPGEDU/UFRGS - slopezrs@ yahoo.com.br, \\ Cláudia Zank - PPGEDU/UFRGS - claudiazank@ gmail.com \\ Patricia Alejandra Behar - PPGEDU/UFRGS - pbehar@terra.com.br
}

Resumo: O mundo globalizado encontra-se em constante processo de transformação, o que exige das organizações rapidez e flexibilidade para se adaptar às mudanças. As equipes de trabalho surgem como uma das respostas a este desafio, impondo aos trabalhadores a necessidade de desenvolver a competência para trabalhar em equipe. Este artigo apresenta conceitos básicos de equipe e de competência e relata uma experiência de constituição de equipe no Editor de Texto Coletivo ETC. As reflexões advindas desta experiência revelam que são as atitudes, principalmente as que demonstram intencionalidade, envolvimento e comprometimento, que mantém a constituição da equipe e possibilitam alcançar os objetivos propostos.

Palavras-chaves: competência, editor de texto coletivo, trabalho em equipe.

\section{The Team Work in a Collective Text Editor}

\begin{abstract}
The globalized world is in a constant process of transformation, which requires from the organizations speed and flexibility in order to adapt to changes. The work teams emerge as a response to this challenge, requiring the workers to develop the competence to work in teams. This article presents basic concepts of team and competence and reports an experience about forming a team in the Collective Text Editor ETC. The reflections arising from this experience show that are mainly the attitudes, especially those that demonstrate intent, involvement and commitment, which keeps up the team together and enable the goals proposed.
\end{abstract}

Keywords: competence, collective text editor, work teams.

\section{Introdução}

O processo de globalização que o mundo está atravessando sujeita empresas e trabalhadores a promoverem ágeis e constantes adaptações. A capacidade de trabalhar em equipe torna-se um dos requisitos exigidos pelas organizações. A competição e o individualismo dão lugar a posturas mais cooperativas, responsáveis e participativas.

Tais movimentos refletem nas exigências para contratação de novos colaboradores. Por conseguinte, os trabalhadores passam a preocupar-se em desenvolver a competência para o trabalho em equipe, uma vez que esta pode lhes proporcionar mais oportunidades de acesso ao mercado de trabalho.

Com o intuito de fornecer subsídios para discussões e reflexões acerca do assunto, foi realizado em 2009/1 um Curso de Extensão denominado "Trabalho em Equipe: Uma Competência a Desenvolver", oferecido pelo Programa de Pós-Graduação em Educação (PPGEDU) da Universidade Federal do Rio Grande do Sul (UFRGS). 
Este artigo é resultado do trabalho de uma equipe constituída durante a realização do referido curso e tem por objetivo relatar a sua experiência com o ETC $^{2}$. Trata-se de um editor de texto coletivo desenvolvido pelo NUTED (Núcleo de Tecnologia Digital aplicada à Educação), da Faculdade de Educação da Universidade Federal do Rio Grande do Sul com o objetivo de propiciar a escrita coletiva/cooperativa por meio da Web.

Na próxima seção se procede a uma breve revisão teórica sobre a evolução da organização do trabalho. Na Seção 3 são feitas considerações a respeito das equipes de trabalho e a Seção 4 aborda a competência para o trabalho em equipe e saberes que formam tal competência. Na Seção 5 é apresentado o ETC (Editor de Texto Coletivo) e a experiência da equipe com o editor. Na última seção, são tecidas as considerações finais.

\section{Organização do Trabalho}

Silva et al. (2004) aduzem ser o artesanato a primeira forma de organização da atividade produtiva, na qual o artesão, sendo o proprietário dos meios de produção, determina tanto a concepção do trabalho como a sua execução. Entretanto, com o tempo, o artesanato passa por várias transformações e $\mathrm{o}$ trabalhador perde gradativamente a sua autonomia diante do processo produtivo, até então solitário.

No final do século XIX, com a Revolução Industrial plenamente difundida nos países centrais da Europa, começam a surgir redefinições na organização do trabalho, impulsionadas pelas máquinas que levariam a enormes ganhos de produtividade. Surge, então, como decorrência do desenvolvimento industrial, a Teoria da Administração Científica (Taylor, 1990). Taylor (1990) estuda os tempos e movimentos dos trabalhadores com o objetivo de aumentar a eficiência e reduzir o desperdício do esforço humano. Por meio da organização racional do trabalho, a especialização nas tarefas executadas é enfatizada, e os trabalhadores, apesar de trabalharem em conjunto, passam a executar suas tarefas isoladamente, numa visão extremamente mecanicista e microscópica do homem.

A divisão e a fragmentação do trabalho, defendida primeiramente por Taylor, serve posteriormente como linha mestra para o Fordismo (Ford, 1967), que não se limita a padronizar tempos e movimentos, escolhendo também o trabalhador mais adequado a cada função. Neste contexto, o trabalhador ideal é aquele que possui as capacidades físicas e intelectuais adequadas a uma tarefa específica. Com Ford surge a ideia da linha de montagem, no qual é a máquina, e não o homem, o elemento central da produção (Ford, 1967).

Após a II Guerra Mundial, entre as décadas de 50 e 70, surge um novo modelo de organização do trabalho, denominado "Modelo Japonês de Organização", também conhecido como Toyotismo (Fleury; Fleury, 1995). Os princípios que norteiam este processo são: raciocínio sistêmico; orientação estratégica; colaboração na competição; uso inteligente e objetivo da informação; integração dos processos de decisão na empresa; e aprendizagem e inovação.

Outra corrente deste mesmo período é a Escola Sócio-Técnica, uma das pioneiras em discutir a necessidade de compatibilização dos ambientes técnicos e sociais do trabalho. A Escola Sócio-Técnica rompe a tradição taylorista de descrição 
detalhada dos cargos e propõe a formação de grupos semi-autônomos, ou autoreguláveis (Biazzi, 1994). Segundo Terra (1999), a Escola Sócio-Técnica antecipa-se aos dias atuais ao propor um modelo de organização que permite que os grupos de trabalho sejam montados e desmontados conforme a necessidade.

De fato, no despertar do século XXI, as organizações contemporâneas, inseridas em um ambiente globalizado e altamente competitivo, necessitam fazer a transição de uma estrutura de relações individuais para uma estrutura de relações de equipes. $\mathrm{Na}$ próxima seção é apresentado o funcionamento destas equipes.

\section{Equipes de Trabalho}

Para Ancona e Nadler (1988), as equipes são grupos de pessoas formados para criar sinergia, para aumentar a aplicação coordenada de conhecimento especializado, a fim de que o desempenho do todo seja maior do que a soma de suas partes. Já

Maximiano (1995a) sugere que a equipe é um grupo de pessoas com um objetivo comum, que pode decidir como fazer para alcançá-lo, e que trabalha dentro de uma área de autonomia definida de comum acordo com a administração.

Por sua vez, Drucker (1998) afirma que a equipe é um grupo, geralmente pequeno, de pessoas que possuem formação, habilitações, conhecimentos diversos e que procedem de vários setores da organização, trabalhando juntas numa área específica. $\mathrm{O}$ autor ainda acrescenta a questão da responsabilidade: em uma equipe cada um de seus membros se sente responsável pelo resultado, uma vez que todos conhecem a tarefa a ser desenvolvida em conjunto. Este estudo utiliza como base o conceito de Drucker (1998).

Ressalta-se, ainda, que hoje em dia existe outro tipo de equipe: as virtuais. Uma vez que as organizações contemporâneas necessitam de novas alternativas estruturais para manterem sua competitividade, desenvolve-se, aos poucos, a estrutura virtual que, segundo Arnold e Hartling citado por Corrêa e Bremer (1997), se traduz em uma maneira de as pessoas, as empresas ou instituições interagirem através da utilização de tecnologia.

A evolução tecnológica vivenciada nos dias atuais modifica a forma de se trabalhar. A tecnologia moderna permite que pessoas trabalhem em constante comunicação com outras pessoas, com o ambiente externo à organização, em diferentes horários, em casa, etc (Hartman et al., 2009).

As equipes virtuais podem trabalhar a distância, estabelecendo metas e participando de processos decisórios dos líderes, mesmo quando as barreiras físicas e/ou geográficas separam seus integrantes. No moderno mundo competitivo, essas barreiras devem ser transpostas para que as equipes se tornem eficientes e eficazes, gerando vantagens competitivas para as organizações. A tecnologia da informação permite que se formem equipes virtuais com facilidade, confiabilidade e baixos custos (Hartman et al., 2009).

Para tanto, podem ser utilizadas tecnologias como e-mail, videoconferência, fóruns e aplicativos de trabalho em grupo como ambientes virtuais, editores de texto coletivo etc. Cada situação e cada objetivo é que definem a melhor ferramenta ou gama de ferramentas a serem utilizadas pelas equipes (Fuks et al., 2002). 
Para Hassegawa (2002), "basicamente, o que distingue a equipe virtual das equipes tradicionais [...] é a característica de transposição de fronteiras e limites físicos ou organizacionais". Neste sentido, a competência para o trabalho em equipe não sofre alterações. A próxima seção trata sobre este assunto, apresentando diferentes conceitos para competência e os saberes que a formam.

\section{Competência para o Trabalho em Equipe}

O termo competência vem sendo associado a diferentes significados. Ao tratar-se de pessoas, pode ser entendido como a competência do indivíduo; com relação às organizações existem as core competences ${ }^{3}$; e, com relação aos países, seu sentido remete aos sistemas educacionais e à formação de competências (Fleury; Fleury, 2001).

Usualmente, competência é o termo utilizado para designar uma pessoa qualificada para realizar alguma coisa, se diferindo dos conceitos de aptidão (talento natural de uma pessoa), habilidade (demonstração prática de um determinado talento) e conhecimento (aquilo que o indivíduo precisa saber para executar uma tarefa) (Fleury; Fleury, 2001).

Ainda assim, o conceito de competência é apresentado por vários autores como sendo um conjunto de aptidões, habilidades e conhecimentos que proporcionam um desempenho superior, associando-se ainda à idéia de que os desempenhos melhores estão diretamente relacionados à personalidade e à inteligência das pessoas (Spencer; Spencer, 1993; Mc Lagan, 1996; Mirabile, 1997 citados por Fleury; Fleury, 2000). Em outras palavras, competência seria um estoque de recursos, um conjunto de capacidades humanas que a pessoa possui (Fleury; Fleury, 2001).

As organizações, a fim de se tornarem (e se manterem) competitivas nos mercados interno e externo, disputam também as competências individuais, procurando atrair para os seus quadros pessoas capazes de combinar capacidades complexas para atender às suas core competences. Neste sentido, a insatisfação decorrente do descompasso entre as necessidades reais das empresas e o processo de formação dos profissionais, eminentemente técnico, estabelece um debate sobre como aumentar a capacitação dos trabalhadores e suas chances de se empregarem (Fleury; Fleury, 2001).

Com foco neste contexto, a reforma educacional ocorrida no final dos anos 90 traz, como princípio norteador da educação profissional de nível técnico, as competências profissionais. Este estudo, portanto, utiliza o conceito de competência disposto no Parecer CNE/CEB n ${ }^{\circ}$ 16/99. Neste documento, competência é conceituada como "a capacidade de articular, mobilizar e colocar em ação valores, conhecimentos e habilidades necessários para o desempenho eficiente e eficaz de atividades requeridas pela natureza do trabalho". O Parecer esclarece ainda que os conhecimentos são os saberes, as habilidades o saber fazer e os valores o saber ser (Brasil, 1999).

\subsection{Saberes para o trabalho em equipe}

Sparapani (2000) atesta que os bons profissionais são aqueles capazes de tomar decisões, pensar de maneira crítica e trabalhar cooperativamente. Complementando a idéia, Chiavenato (1996) afirma que os profissionais considerados excelentes não são os que apresentam sinais fortes de competitividade e espírito individualista. Atualmente, 
privilegia-se a capacidade de cooperação, a facilidade para trabalhar em conjunto com outros indivíduos e o espírito de equipe.

Fleury e Fleury (2001) apresentam ponto de vista semelhante. Os autores afirmam que a capacidade de trabalhar em constante interação com os outros, ou seja, em equipe, condiciona outros fatores, como experiência profissional, conhecimentos adquiridos e competência técnica. Para os autores, os saberes que um profissional deve possuir são os seguintes: saber agir; saber mobilizar recursos; saber comunicar; saber aprender; saber engajar-se e comprometer-se e saber assumir responsabilidades.

Já para Gramigna (2002), é o conjunto de atitudes agregadas ao agir cotidiano que distingue os profissionais de vanguarda. Afirma a autora que, para trabalhar em equipe, mais do que o conhecimento e as habilidades, o indivíduo deve desenvolver atitudes, pois são elas que vão determinar o nível de confiança entre os seus integrantes, o ambiente de trabalho e a orientação comprometida com as metas e os objetivos organizacionais. Algumas das atitudes mais importantes elencadas por Gramigna (2002) para trabalhar em equipe são: possuir sensibilidade interpessoal; possuir energia e iniciativa para a resolução de problemas; possuir disponibilidade para ouvir; ser curioso e interessado; ser ético e honesto; ser comprometido com resultados e possuir flexibilidade e bom senso no trato com as pessoas.

Mas como mobilizar estes saberes e desenvolver a competência para o trabalho em equipe? Segundo Ribas Jr. (2003), é aprendendo a aprender. O princípio pedagógico do aprender a aprender vem da pedagogia construtivista, segundo a qual os alunos fazem reflexões e constroem conceitos a partir de vivências, durante as quais se relacionam ativa e significativamente com os objetos do conhecimento. Essa metodologia busca desenvolver nos indivíduos competências que lhes proporcionem autonomia para agir na gestão do seu próprio desenvolvimento cultural. Parte-se do pressuposto que uma boa educação não contempla somente os conteúdos a serem aprendidos pelos alunos, mas inclui também as competências que ali podem ser desenvolvidas (Ribas Jr., 2003).

A educação que segue o princípio pedagógico do aprender a aprender deve ser prática e dinâmica. As situações criadas devem permitir que o aluno possa reconhecer as características dos outros, as tendências e os desafios da realidade e as suas próprias capacidades. (Ribas Jr., 2003).

Neste sentido, entende-se que o ETC tem potencial para ser utilizado no desenvolvimento da competência para o trabalho em equipe. Por meio das ferramentas de interação, o editor possibilita aos usuários se organizar e constituir uma equipe. A

próxima seção trata deste editor e da experiência da equipe com a escrita coletiva no ETC.

\section{O ETC e a Experiência da Equipe}

O ETC se constitui em um editor de texto coletivo desenvolvido pelo NUTED/ UFRGS com o objetivo de propiciar a escrita coletiva cooperativa através da Web. A necessidade de sua construção surge a partir das dificuldades observadas na elaboração de trabalhos coletivos, mais precisamente nos cursos à distância, por meio da rede.

Por ser um ambiente de trabalho cooperativo/colaborativo, o ETC permite uma concepção de aprendizagem que se configura pela coordenação de ações do sujeito 
sobre um objeto (Piaget, 1973). Neste sentido, o usuário constrói seu conhecimento na interação com os outros participantes, com os recursos e funcionalidades do ambiente, materiais publicados, produções dos demais usuários e os seus próprios registros. Para tanto, o ambiente oferece condições de trocas entre os participantes por meio de funcionalidades destinadas à interação entre os sujeitos envolvidos (Zank et al., 2008).

Estas funcionalidades são chamadas de funcionalidades de apoio e, além de promover a interação/comunicação entre os usuários, também proporcionam $\mathrm{o}$ armazenamento e consulta de conteúdos relacionados. São funcionalidades de apoio os Dados Pessoais (perfil do usuário); Fórum (para discussão de assuntos referentes ao texto); e Biblioteca (para armazenamento de materiais de apoio). Além dessas funcionalidades, existem ainda as de navegação principal, relacionadas com a criação e edição dos grupos e textos.

É por meio das funcionalidades de navegação principal, que o ETC propõe aos participantes uma relação linguística aberta, pela reconstrução constante da palavra do outro, sendo possível a interferência entre os sujeitos envolvidos na escrita e na sua interpretação. Assim, o texto caracteriza-se por ser passível de mudanças e transformações, ganhando novos encaminhamentos conforme as contribuições vão sendo inseridas (Behar et al., 2005).

Na prática, a construção coletiva de um texto, como foi a situação vivenciada para a produção do presente artigo, deve ser marcada na cooperação e respeito pela opinião contrária. Deste modo, segundo Behar et al. (2005), para o equilíbrio é necessária a presença de uma escala comum de valores, através da qual os sujeitos podem compreender os signos utilizados pelo grupo. Os mesmos autores também afirmam que não se pode considerar o resultado de um texto coletivo como um aglomerado de informações, e sim como um todo correspondente, recíproco e complementar, produto de inúmeras trocas e transformações.

A organização e a responsabilidade de cada um dos integrantes da equipe é ponto fundamental para a composição de textos em ambiente virtual. A experiência obtida demonstra que, sem o estabelecimento claro do objetivo a ser alcançado e de prazos a serem cumpridos, a produção virtual fica comprometida. Sobre esta experiência, faz-se agora uma breve descrição.

Em 2009/01 o NUTED/UFRGS realizou o Curso de Extensão "Trabalho em Equipe: Uma Competência a Desenvolver". Este teve como objetivo proporcionar momentos de discussão e reflexão. Também forneceu subsídios para que os participantes pudessem desenvolver a competência para trabalhar em equipe por meio da escrita coletiva no ETC. Por ser aberto à comunidade, formou-se um grupo bastante heterogêneo, composto por estudantes de nível técnico, graduação e pós-graduação.

A modalidade foi semipresencial, com 02 aulas presenciais e 02 aulas a distância. Na primeira aula presencial, foram formadas as equipes. Estas tinham por objetivo desenvolver um texto em formato de artigo científico e apresentá-lo no último dia de aula. O presente artigo é, então, o resultado de um trabalho em equipe realizado por meio do ETC durante o referido Curso de Extensão.

A partir desta experimentação no editor se faz uma breve apresentação das estratégias utilizadas pelos membros para formar a equipe e realizar a tarefa proposta. Parte-se, então, para uma reflexão acerca dos saberes pertinentes ao trabalho em equipe que foram colocados em ação pelos participantes. São analisadas ainda as 
funcionalidades do ETC que melhor contribuíram para a realização da tarefa proposta e, por conseguinte, da constituição da equipe.

Composta por quatro integrantes, a equipe adotou como estratégia inicial postar mensagens no fórum do ambiente a fim de definir o tema que seria desenvolvido. Feita a escolha, deu-se a abertura do texto no editor de texto coletivo por iniciativa de um dos integrantes. As tarefas para a escrita foram divididas e os prazos estabelecidos. Dois integrantes concordaram com a proposta e um discordou, abandonando a equipe. Os três membros restantes seguiram com a proposta inicial. Basicamente, a estratégia de realização da tarefa, a partir desse momento, era postar o texto no ETC, os membros lerem e opinarem. As alterações sugeridas eram, então, promovidas por um dos integrantes da equipe, o gerente do texto, que atualizava as versões.

Dos saberes elencados na seção anterior, destacaram-se nos participantes a flexibilidade e a adaptabilidade, demonstrando ter atitude aberta e receptiva a inovações (Gramigna, 2002). Tais saberes foram essenciais para dar início ao processo de constituição de equipe no editor, pois permitiram aos integrantes o domínio da ferramenta, até então desconhecida.

Acrescenta-se, ainda, que a experiência de constituição de equipe no ETC foi marcada pelo saber engajar-se e saber comprometer-se, aceitando as regras estabelecidas e atentando ao seu correto cumprimento. Tal equilíbrio só pode se estabelecer devido à presença de uma escala comum de valores e devido à compreensão dos signos utilizados pelos integrantes da equipe (Behar et al., 2005).

Na prática, a construção coletiva de um texto, como foi a situação vivenciada para a produção do presente artigo, deve ser marcada na cooperação e respeito pela opinião contrária. Deste modo, segundo Behar et al. (2005), para o equilíbrio é necessária a presença de uma escala comum de valores, através da qual os sujeitos podem compreender os signos utilizados pelo grupo.

O que não minimiza a importância do saber engajar-se e comprometer-se, aceitando as regras estabelecidas e atentando ao seu correto cumprimento, o que supõe a presença de uma escala comum de valores e a compreensão dos signos utilizados pelos integrantes da equipe (Behar et al., 2005).

A partir dos estudos teóricos e desta experiência, percebe-se também a importância da disponibilidade para ouvir o outro, com respeito e sensibilidade interpessoal (Gramigna, 2002), o que estabeleceu uma interação harmoniosa e produtiva da equipe. $\mathrm{O}$ resultado obtido revela ainda que, efetivamente, as atitudes, mais do que o conhecimento e as habilidades individuais de cada um dos integrantes, foram determinantes para o estabelecimento da confiança necessária entre os usuários para a construção do texto, conforme refere Gramigna (2002).

Tais reflexões vão ao encontro do conceito de competência proposto no Parecer CNE/CEB 19/99. Por meio das funcionalidades do ETC, os participantes tiveram a possibilidade de "(...) colocar em ação valores, conhecimentos e habilidades necessárias para o desempenho eficiente e eficaz de atividades requeridas pela natureza do trabalho" (Brasil, 1999), neste caso, o trabalho em equipe.

Neste contexto, as atitudes em relação ao outro e as trocas que efetivamente permeiam a sensibilidade interpessoal (Gramigna, 2002) ocorreram por meio das funcionalidades de comunicação/interação disponíveis no ambiente. Salienta-se o Fórum para trabalhar a motivação e fazer trocas relacionadas aos conhecimentos 
técnicos e a funcionalidade "Comentários", muito utilizadas para bilhetes e lembretes, os quais também foram escritos no espaço de edição do texto. Naturalmente, as funcionalidades que compõem a edição (funcionalidades de navegação principal) foram as que mais contribuíram para a realização da tarefa, uma vez que permitem a alteração do texto por meio de modificações, inserções e exclusões.

Entende-se que a constituição de equipe foi um processo que se deu a partir da discussão de aspectos teóricos concomitante à construção coletiva. Apreender e dominar o ambiente ETC, bem como desenvolver uma sistemática para o cumprimento da tarefa são partes deste processo.

\section{Considerações Finais}

O perfil mais comum aos trabalhadores se calcava no individualismo. Os países e suas economias eram, no entanto, mais estáveis. Desde as últimas décadas do século passado essa estabilidade deu lugar a um mundo globalizado, instável e que sofre alterações radicais a curtos espaços de tempo. Na busca pela sobrevivência nos mercados externo e interno, as organizações buscam agilidade e rápida adaptação às mudanças.

O trabalho em equipe surge então como uma das estruturas viáveis para esse novo cenário, fazendo com que o perfil do profissional contemporâneo se modifique radicalmente. Um dos requisitos mais solicitados pelas organizações passa a ser a competência para trabalhar em equipe.

Compreende-se equipe como um grupo de pessoas que não só tem um objetivo em comum, mas que se sente responsável pelo resultado, reconhecendo a importância do outro neste processo. Dentro deste entendimento, as equipes virtuais apenas diferem das tradicionais por utilizarem as tecnologias de informação e comunicação para interagir e realizar a tarefa proposta.

As competências permitem ao sujeito colocar uma gama de saberes em ação e são desenvolvidas a partir de um princípio pedagógico que prioriza o aprender $a$ aprender. Neste sentido, os alunos devem refletir e construir conceitos a partir de suas vivências e da interação com o outro, integrando prática e teoria.

O ETC possibilita uma escrita coletiva cooperativa e regida pelo equilíbrio e coordenação de diferentes pontos de vista. A experiência obtida na construção virtual do presente artigo mostra que o editor pode ser um espaço que propicie aos sujeitos colocar em ação saberes formadores da competência para o trabalho em equipe. Dentre estes, destaca-se o compromisso com resultados e a capacidade de compreender e trabalhar conteúdos, às vezes estranhos ao cotidiano, com sinergia e flexibilidade. Salienta-se, no entanto, que é necessária a intencionalidade por parte dos participantes, ou seja, a atitude de envolver-se e ter compromisso com os resultados.

\section{Notas de Texto}

1 Este trabalho vincula-se ao projeto de pesquisa "Trabalho em Equipe: uma competência para a laboralidade por meio do ETC" em desenvolvimento no PPGEDU/UFRGS com apoio do CNPq.

2 Disponível em: http://homer.nuted.edu.ufrgs.br/etc/ 
${ }^{3}$ Core Competences são competências estratégicas, únicas e distintivas de uma organização.

\section{Referências Bibliográficas}

ANCONA, D.G.; NADLER, D.A. Top hats and executive tales: designing the senior teams. Group and Organization Studies. 1988.

BEHAR, P.A et al.. Construção e aplicação do ETC - Editor de Texto Coletivo. In: Barbosa, R.M. (Org.). Ambientes virtuais de aprendizagem. Porto Alegre : Artmed. 2005. 184p.

BIAZZI, F. O Trabalho e as organizações na perspectiva Sócio-Técnica. 1994.

BRASIL. Parecer CNE/CEB n $\mathbf{n}^{\mathbf{1}}$ 16/99, de 5 de outubro de 1999. Trata das Diretrizes Curriculares Nacionais para a Educação Profissional de Nível Técnico. In: Portal Ministério da Educação e Cultura. Disponível em: http://portal.mec.gov.br/setec/arquivos/pdf/PCNE_CEB16_99.pdf. Acesso em: 25 jan. 2009.

CHIAVENATO, I. Como transformar RH (de um centro de despesa) em um centro de lucro. São Paulo, Makron Books. 1996.

CORRÊA, G.N.; BREMER, C.F. (1997). Experiências práticas em organizações e empresas virtuais. In Encontro Nacional de Engenharia de Produção. Anais. $17^{\circ}$ Enegep, Gramado, RS.

DRUCKER, P. Introdução à administração. 3a. edição. São Paulo, Pioneira. 1998.

FLEURY, A.; FLEURY, M. T. L. Aprendizagem e inovação organizacional: as experiências do Japão, Coréia e Brasil. São Paulo: Atlas. 1995.

FLEURY, A.; FLEURY, M. T. L.. Estratégias empresariais e formação de competências. São Paulo: Atlas. 2000.

FLeURY, M. T. L.; FleURY, A. C. C. Construindo o conceito de competência. RAC, Edição Especial. 2001. p. 183-196.

FORD, H. Os princípios da prosperidade. São Paulo: Livraria Freitas Bastos. 1967.

FUKS, H.; RAPOSO, A.B.; GEROSA, M.A. Engenharia de Groupware: Desenvolvimento de Aplicações Colaborativas. In: XXI Jornada de Atualização em Informática. Anais do XXII Congresso da Sociedade Brasileira de Computação, 2002. v. 2, Cap. 3, ISBN 85-88442-24-8, pp. 89-128. 
GRAMIGNA, M. R. Modelo de competências e gestão de talentos. São Paulo: Makron Books. 2002.

HARTMAN, A.; SILVA, F.G.; REIS, D.R.; SCANDELARI, L.. As equipes virtuais promovendo vantagens competitivas na Bungue Fertilizantes S/A. In: PILATTI, L.A.; KOVALESKI, J.L.; OLIVEIRA, L. (Orgs.). Temas em Engenharia de Produção. 1. Ed. Jundiaí: Fontoura Editora Ltda, 2005, v.1. Disponível em: http://pg.cefetpr.br/ppgep/livro/8_Adriane_Hartman.pdf. Acesso em: 26 jan. 2009.

HASSEGAWA, L.N. O papel das interfaces no sucesso de projetos utilizando equipes virtuais. São Paulo: USP, 2002. Dissertação (Mestrado em Administração de Empresas) - Faculdade de Economia, Administração e Contabilidade, Universidade de São Paulo, São Paulo. 2002.

MAXIMIANO, A.C.A. Além da hierarquia: como implantar estratégias participativas para administrar a empresa enxuta. São Paulo, Atlas. 1995.

PIAGET, J. Estudos Sociológicos. Rio de Janeiro: Forense. 1993.

RIBAS JR, F.B. Competências básicas para o trabalho. In: Prattein Consultoria em Educação e Desenvolvimento Social. 2003. Disponível em: http://www.prattein.com.br/prattein/dados/anexos/68.pdf. Acesso em: 30 jan. 2009.

SILVA, J.O.; NAZZARI, R.K.; LAZZAROTTO, E.M.; PONTES FILHO, A.P. Paradigmas da Organização do Trabalho em Finais do Século XX. In: III Seminário do Centro de Ciências Sociais Aplicadas, 2004, Cascavel. Anais do III Seminário de Ciências Sociais Aplicadas, 2004. v. 1. p. 1-9. Disponível em: .

http://www.unioeste.br/campi/cascavel/ccsa/IIISeminario/paineis/Painel\%2015.pdf.

Acesso em: 23 jan. 2009.

SPARAPANI, E.F. et al Cooperative learning: an investigation of the knowledge and classroom practice of middle grades teachers. Education Magazine. 2000. Disponível em: http://www.britannica.com/bcom/magazine/article/0,5744,219312,00.html. Acesso em: 15 maio 2009.

TERRA, J.C.C. Aspectos Conceituais e Estudo Exploratório Sobre as Práticas de Empresas Brasileiras. São Paulo: USP, 1999. Tese de Doutorado. Disponível em: http://www.terraforum.com.br/sites/terraforum/paginas/teses/teses.aspx. Acesso em: 10 jun. 2009

TAYLOR, F.W. Princípios da Administração Científica. $8^{a}$ ed. São Paulo: Atlas. 1990.

ZANK, C.; TIELLET, C.A.B.; CUNHA, C.R.; LONGHI, M.T.; SCHMITT, M.A.R.; BEHAR, P.A. Construção de textos coletivos experiências através de um Groupware. 2008 In: V Congresso Brasileiro de Educação Superior a Distância (ESUD) e $6^{\circ}$ 
Seminário Nacional de Educação a Distância (SENAED). Gramado. São Paulo: ABED. 